\title{
COMPREHENSIVE EVALUATION OF DIFFERENT VERTICAL BOOM SPRAYER NOZZLES FOR GREENHOUSES
}

\author{
S. M. Younis ${ }^{1}$, K. M. Abdelbary ${ }^{2}$ and M. S. M. Metawe $^{3}$
}

\begin{abstract}
Recent research work deals with using vertical spray booms for the safe and efficient application of crop protection chemicals in greenhouses. Nozzle type and setting significantly affect spray deposition and crop nutrition and should be carefully considered. Six different types of nozzles were tested and calibrated with two operating pressures for each and different spacing between nozzles. Wetted radius, precipitation rate, discharge were measured and calculated. Nozzle types included: Copper nozzle, Plastic nozzle with four exits, Single fogger (naandan $\left.{ }^{\circledR}\right)$, Oblique nozzle, Rondo flow-regulated mini sprinkler (green) (RFR) and Rondo mist sprayer (violet). Copper nozzle was recommended for further aspects of selection and technical evaluation. It is demonstrated the best delivery of pest and the best distribution in the lap and inside the greenhouse after testing.
\end{abstract}

Keywords: greenhouse, delivery, pest management, environment, vertical boom, prototype, distribution, spray deposition.

\section{INTRODUCTION}

7 he closed environment of a greenhouse has its own unique requirements, compared with outdoor production. Pests and diseases, and extremes of heat and humidity, have to be controlled. Greenhouses are often used for growing flowers, vegetables, fruits and tobacco plants. The density of plants in the greenhouse provides a favorable climate for the spread of pests and diseases that cause a great loss in crop quality and quantity. To control these diseases growers use pesticides extensively which led to various problems such as (1) increase in production costs,

\footnotetext{
${ }_{1}^{1}$ Prof., Agric. Eng. Dept., Fac. of Agric., Cairo Univ., Giza, Egypt.

${ }^{2}$ Assist. Prof., Agric. Eng. Dept., Fac. of Agric., Cairo Univ., Giza, Egypt.

${ }^{3}$ M. Sc. Student, Agric. Eng. Dept., Fac. of Agric., Cairo Univ., Giza, Egypt.
} 
(2)emergence of new strains of pathogens, which is resistant to pesticides pollution of crops and environment. Equipment for applying pesticides can be simply as a hand-held squirt bottle or as complex as a multiplenozzle pressure sprayer. Size and type of area to be treated are the most important considerations to select appropriate spraying equipments.

Application of nutrients, fungicides and pesticides are critical to successful greenhouse production, where spraying plays a very important role in reducing production losses. Research suggests that between 30 and $35 \%$ of production losses can be saved when harmful insects and diseases are eliminated by spraying. However, chemical runoff associated with over application can have serious environmental consequences. Due to the toxicity of some application materials, this process can be extremely hazardous to operators,(Burks, 2006).Interior support structures as well as small walkways and alleys limit the size of equipment and maneuverability. Hand-held applicators are frequently used to apply pesticides in greenhouses because of limitations on the structure or operating space (Derksenet al., 2009)

Van Os et al., (2005)in their experimental greenhouse, growing a tomato crop, mentioned that if a reduction in spray pressure could improve the spray result, while, simultaneously, emission to the ground could be reduced. Otherwise, In the other hand spray drift reduced dose than intended on the target field, which can reduce the effectiveness of the pesticide, wasting pesticide and money, (Nuyttens et al., 2007and Nuyttens et al., 2009).

Abuarab et al., (2008).mentioned that in order to reduce energy consumption and lower operating costs, sprinkler systems should operate at the lowest pressure at which acceptable application uniformity and efficiency can be achieved. Sprinkler manufacturer's catalogs usually identify a recommended range of operating pressure that results in acceptable performance for each sprinkler. The design operating pressure should be as low as possible and within the recommended range. In general, highest uniformities are obtained at spacings of $40 \%$ or less of the wetted diameter, but such close spacings raise both precipitation rates and system cost. Thus, they can be utilized only for cash crops. Overly or wide spacings between lines can result in poor uniformities of coverage 
Spray deposits tended to increase when using a fine, rather than a medium quality spray, with the largest increase at the earlier growth stage using the lower volume application rate (100 1/ha), gave substantially higher deposits than the conventional volume rate (200 1/ha) (Miller et al., 2001).Greenhouse pesticide labels lack specific recommendations on the spray volume and spray droplet sizes, which will provide the most efficacious pest management(Derksenet al., 2007a). Spray droplets depend on a number of working pressure and ambient conditions at the time of application, (Fritz et al., 2010).Angling the delivery of the spray also increased the level of deposit at the earlier growth stage, as expected penetration into the canopy was much greater for the smaller canopy condition at the earlier growth stage and that the deposit levels per unit of plant weight, are consistently higher at the earlier growth stage(Miller et al., 2001).

Nuyttens et al., (2004) used a quantitative method with mineral chelates to evaluate spray deposits and distributions within tomato and pepper canopies inside greenhouses. They demonstrated that the spray with $0.35 \mathrm{~m}$ nozzle spacing provided a much better spray distribution than that with $0.50 \mathrm{~m}$ nozzle spacing. Optimal spray distance for $80^{\circ}$ flat fan nozzles with the $0.35 \mathrm{~m}$ nozzle spacing was about $0.30 \mathrm{~m}$.

Braekmanet al.,(2007) reported that increasingly, Flemish greenhouse growers are using spray booms instead of spray guns to apply plant protection products. Although the advantages of spray booms are well known, growers still have many questions concerning nozzle choice and settings. The standard vertical spray boom performed better than the reference spray equipment in strawberries (spray gun) and in tomatoes (air-assisted sprayer). Nozzle type and settings significantly affected spray deposition and crop nutrition. The use of a vertical spray boom is a promising technique for applying plant protection products in a safe and efficient way in tomatoes and strawberries, and nozzle choice and setting should be carefully considered. Spray boom systems instead of the still predominantly used spray guns might improve crop protection management in greenhouses considerably. Application rate, nozzle type, and configuration might influence the spray deposition and, as such, its efficiency (Braekman et al.,2009). 
The objective of this study was to perform a comprehensive evaluation of different types of nozzles. The evaluation were conducted in two stages, the first evaluation tests were laboratorial trials to eliminate the candidate nozzles, the second was field experiment to test the actual technical performance parameters of the chosen nozzle .

\section{MATERIALS AND METHODS}

\section{Laboratory tests}

a- Nozzle calibration

Nozzle calibration tests were carried out at irrigation lab., Agricultural Engineering Research Institute (AREI).

Six different types of nozzles were used to test and calibrate their Wetted radius, rate of precipitation (ROP), distribution uniformity (DU), christiansen uniformity(CU)and discharge with various operating pressures (.25-.5-.75-1 and 1.25 bar) using water. Nozzle types included :( Copper nozzle, plastic nozzle with for exit, Single fogger (naandan ${ }^{\circledR}$ ), Oblique nozzle, Rondo flow-regulated mini sprinkler (green) (RFR) and Rondo mist sprayer (violet).

- Nozzle discharge was calculated using the following equation:

$$
Q=\frac{g}{t} X \frac{60}{1000}
$$

Where:

$\mathrm{Q}=$ nozzle discharge $(1 / \mathrm{h})$.

$g=$ collected water weight $(\mathrm{g})$.

$\mathrm{t}=$ the duration time of test(min) (3 minutes).

Different working pressures 0.25 bar to3bar, were considered with the purpose of assessing their effects on wetting radius and discharge rate. According to the manufacturer specifications, the nozzle can be operated well under a pressure between 1, 2 and 3 bar.

Precipitation rate was determined by using rainfall catch-cans For specifying the best shape of water distribution over the soil surface, the application uniformity was determined to judge how evenly the water distribution for different discharges, operating pressures and nozzle heights. 
- The precipitation rate, $\operatorname{Pr}$, is the average volume of water in the form of rain that falls per unit of area and per unit of time at the site. It is measured in units of volume per area per time.

- Rate of Precipitation:

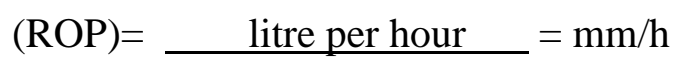

spacing $(\mathrm{m}) \mathrm{x}$ spacing $(\mathrm{m})$

Spacing $=$ nozzle wetted radius

- Application uniformity was estimated using Christiansen uniformity coefficient (CU) and distribution uniformity (DU). The Christiansen uniformity coefficient is a parameter that is widely used to evaluate application uniformity, was developed as follows by (Christiansen, 1942):

$$
C U=\left(1.0-\frac{\sum x}{n . m}\right) 100 \cdots \cdots \cdots
$$

Where:

$\mathrm{CU}=$ Christiansen uniformity coefficient $\mathrm{n}=$ number of observations

$\mathrm{x}=|\mathrm{z}-\mathrm{m}|=$ the total absolute value of deviations from average of the amount of water measured in all accumulation containers.

$\mathrm{z}=$ Individual depth of catch observations from uniformity test

$\mathrm{m}=(\Sigma \mathrm{z}) / \mathrm{n}=$ Average amount of water

-Distribution uniformity is a ratio expressed in a percent of the average low-quarter amount of water caught or infiltrated to the average amount caught or infiltrated as expressed in the following equation (James Larry, 1988).

$$
D U=\frac{\bar{X}_{L O}}{\bar{X}} 100
$$

Where:

$\bar{X}_{L O}$ : The average low-quarter amount of water caught or infiltrated $(\mathrm{mm})$ (the $25 \%$ of the collections with the lowest collection amount)

$\bar{X}$ : The average amount caught or infiltrated $(\mathrm{mm})$ 
- Nozzle height of $30 \mathrm{~cm}$ was considered to evaluate its effect on water distribution pattern. Wetted radius was calculated by measuring the wetted area under the nozzle.

\section{Field experiments}

a- Prototype

Vertical spray boom prototype was designed to deliver the pesticide with high efficiency, management and properly distributions. The used spray liquids were water, MALASON/CHEMINOVA 57\% and Lambada Cyhalothrine $5 \%$.

\section{Specifications of designed prototype are illustrated in the following} table:

Specifications:

Motor:

Weights \&dimensions:

Electrical motor , ( $50 \mathrm{rpm}$ ), 1 phase, Empty weight $150 \mathrm{~kg}$, Maximum maximum speed $1 \mathrm{kmlh}$ weight $300 \mathrm{~kg}$, Total length $1.5 \mathrm{~m}$ ,Nozzle bar height $1 \mathrm{~m}$, Total width 65

Spraying system (nozzles): $\mathrm{cm}$

Spraying system discharge: $\mathrm{Q}=60 \mathrm{Llm}$

Dynamic head : Hmax $40 \mathrm{~m}$

Other features:

Suction Head $\max =9 \mathrm{~m}$

Seat with proper height, Hand Brake

b- Greenhouse:

Field experiments were performed at greenhouses that located in, Department of Ornamental Plants, Fac. of Agric., Cairo University. Greenhouse was used for ornamental plants breeding (internal and external ornamentals) on small pots arranged in ground directly and it was divided into basins, 4 meters wide on the right and left of the main greenhouse axis ( $1 \mathrm{~m}$ width). It was planted with nursery plants (with different heights, shapes, density and some macrophytes). The greenhouse was equipped with a cooling system that consisted of two extracting fans $(1 \mathrm{~m}$ width and $1 \mathrm{~m}$ height) cooling pads had a dimensions of 1.5 high and 2.5 wide. 
Gabel greenhouse (even span trussed roof) was used with galvanized steel structural material. It had a green fiberglass (forced rain plastic (FRP)with $1 \mathrm{~mm}$ thickness)as a cover material. Its standard dimensions were, $9 \mathrm{~m}$ width, $30 \mathrm{~m}$ length and height of $2.5 \mathrm{~m}, 3.75$ to the span . Actual length was 27.5 meters with 2.5 meters at the end of the greenhouse for services and storage.

c- Water-receiving paper

Water receiving paper (Double Ring 102 qualitative filter paper)with diameter $150 \mathrm{~mm}$, had been coated in water mixture with floral blue color substance and left to full dry, then it was used as a receiving paper in the greenhouse. Water receiving papers were fixed on the plants leaves to receive spray droplets that left marks of the falling drop. This method was used to count the distribution droplets, measure the delivery and appropriate coverage of the plant inside the greenhouse.

\section{Results and Discussion}

\section{1- Laboratory experiments results}

Laboratory experiments were performed on six types of nozzle to evaluate their performance with respect to precipitations rate. For each nozzle several observation were recorded, when cans were spaced at 20,40,80 and $120 \mathrm{~cm}$ Nozzle height was adjusted at $30 \mathrm{~cm}$. Each observation was run for 15 minutes under 1 bar working pressure. Water distribution pattern was illustrated by drawing contour map fig $(1,2,3,4,5,6)$. In addition, the wetted radius was measured, distribution uniformity (DU) and christiansen uniformity (CU) were calculated.

The following table summarizes the measured and the calculated parameters of comparison between the different types of nozzle.

\section{Comparison between different types of nozzles:}

\begin{tabular}{|l|l|l|l|l|l|}
\hline $\begin{array}{l}\text { Nozzle type } \\
\text { measurements }\end{array}$ & $\begin{array}{l}\text { Wetted } \\
\text { radius }\end{array}$ & DU \% & CU \% & $\begin{array}{l}\text { Flow rate and } \\
\text { operating pressure }\end{array}$ & $\begin{array}{l}\text { ROP } \\
\mathrm{mm} / \mathrm{h}\end{array}$ \\
\hline Copper & $80 \mathrm{~cm}$ & $50 \%$ & $51.6 \%$ & $\mathrm{Q}=16.729 \mathrm{p}^{0.4461}$ & 26.1 \\
\hline Plastic nozzle with for exit & $40 \mathrm{~cm}$ & $6.4 \%$ & $37 \%$ & $\mathrm{Q}=37.079 \mathrm{p}^{0.4585}$ & 231.7 \\
\hline Oblique nozzle & $80 \mathrm{~cm}$ & $9.9 \%$ & $17.6 \%$ & $\mathrm{Q}=34.65 \mathrm{p}^{0.443}$ & 54.1 \\
\hline Rondo flow-regulated & $120 \mathrm{~cm}$ & $14 \%$ & $16 \%$ & $\mathrm{Q}=35.35 \mathrm{p}^{0.516}$ & 24.5 \\
\hline Single fogger (naandan $\mathbb{R})$ & $20 \mathrm{~cm}$ & $72 \%$ & $57 \%$ & $\mathrm{Q}=4.033 \mathrm{p}^{0.423}$ & 100.8 \\
\hline Rondo mist sprayer (violet) & $80 \mathrm{~cm}$ & $5.1 \%$ & $18 \%$ & $\mathrm{Q}=33.41 \mathrm{p}^{0.482}$ & 52.2 \\
\hline
\end{tabular}


For detailed analyzes of the performance of the six treated nozzle, the relationship between the operating pressure and the related flow rate was graphically demonstrated and mathematically generated. Average flow rate versus operating pressure (.25-.5-.75-1 and 1.25 bar for 3 minutes) for 3 replicates was calculated. This analysis helped to get precious appraising of the tested nozzles.

Generally, in the six types of nozzle, the relationships followed a similar trend that fit power function. As the operating pressure increased, the nozzle flow rate increased within the range of the specified pressures.

-For Copper nozzle (19 observations, cans spaces $40 \mathrm{~cm}$ ), was ranged between 2.2 to $26.2 \mathrm{~g}$ of water. The following contour map illustrates water distribution, nozzle location, cans places and collected water values for copper nozzle.

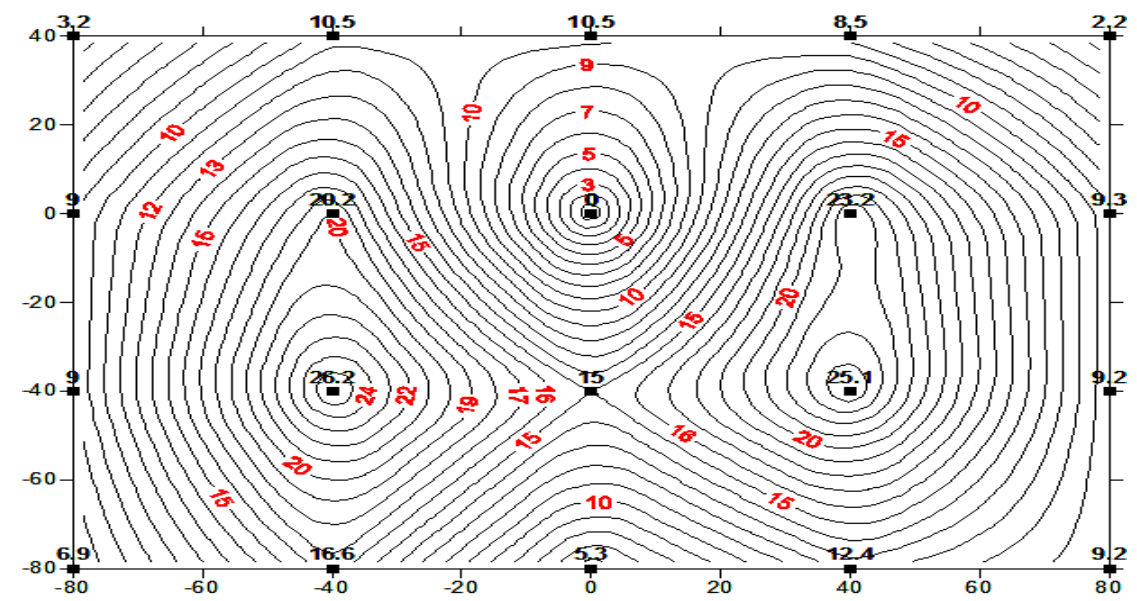

Fig.(1). Water distribution pattern, nozzle place, cans paces and collected water values for copper nozzle.

Average flow rate ranged between 9.11 and $18.87 \mathrm{~L} / \mathrm{h}$.as shown in figure (7).

-For Plastic nozzle with four exit ( 24 observations, cans spaces $20 \mathrm{~cm}$ ), was ranged between 0.1 to $35.1 \mathrm{~g}$ of water. The following contouring map illustrates water distribution, nozzle place, cans paces and collected water values for Plastic with 4 exit nozzle. 


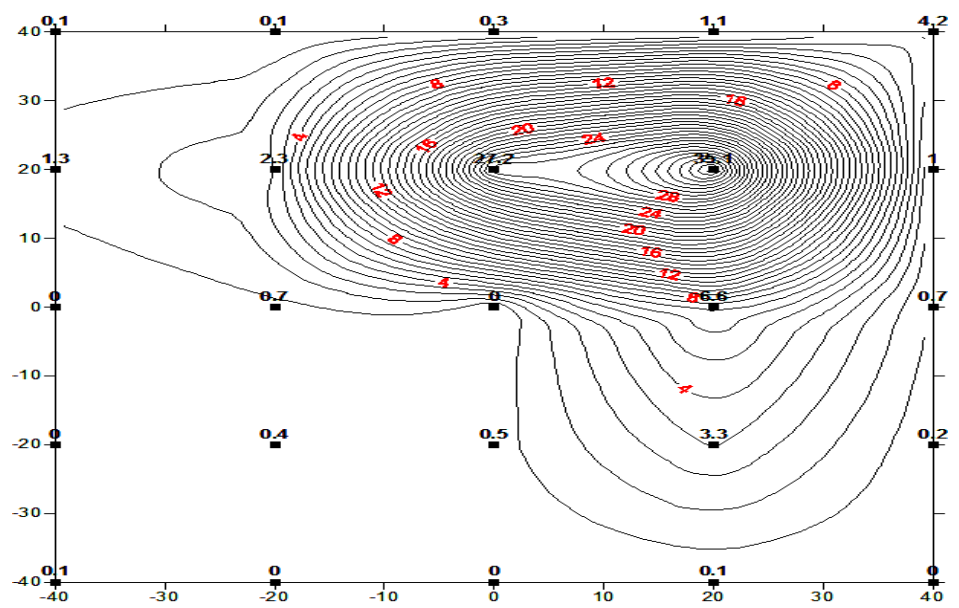

Fig. (2). Water distribution pattern, nozzle place, cans spaces and collected water values for Plastic with 4 exit nozzle.

Average flow rate ranged between 19.48 and $41.12 \mathrm{~L} / \mathrm{h}$.as shown in figure (8).

The highest discharge was obtained in case of plastic nozzle with four exits working at the different operating pressures.

On the other hand, the copper nozzle provided the lowest flow rate at the same working conditions.

-For oblique nozzle (23 observations, cans spaces $40 \mathrm{~cm}$ ), was ranged between 0.2 to $27.8 \mathrm{~g}$ of water. The following contour map illustrates water distribution, nozzle location, cans places and collected water values for oblique nozzle.

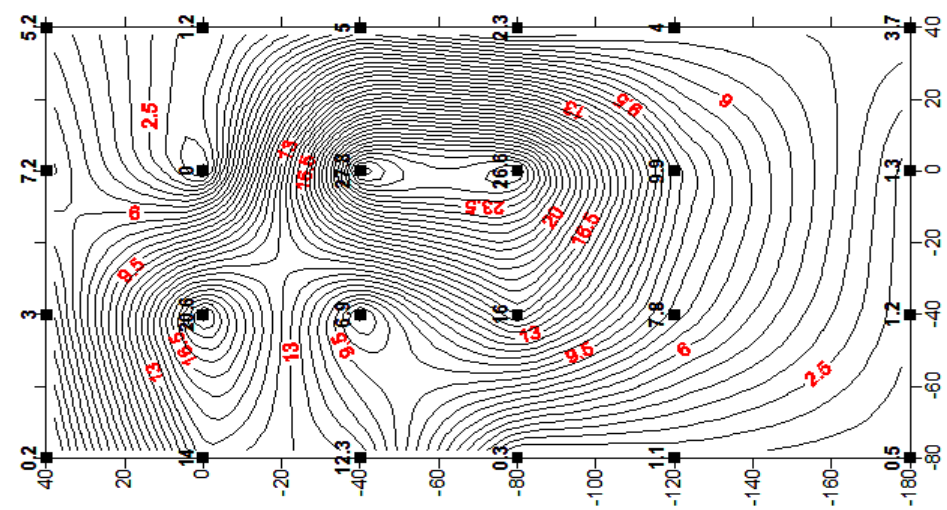

Fig. (3). Water distribution pattern, nozzle place, cans spaces and collected water values for Oblique plastic nozzle. 
Average flow rate ranged between 18.83 and 38.29 L/h.as shown in figure (8).

-For Fogger, (12 observations, cans spaces $5 \mathrm{~cm}$ ), was ranged between 0.8 to $5 \mathrm{~g}$ of water. The following contour map illustrates water distribution, nozzle location, cans places and collected water values for Fogger.

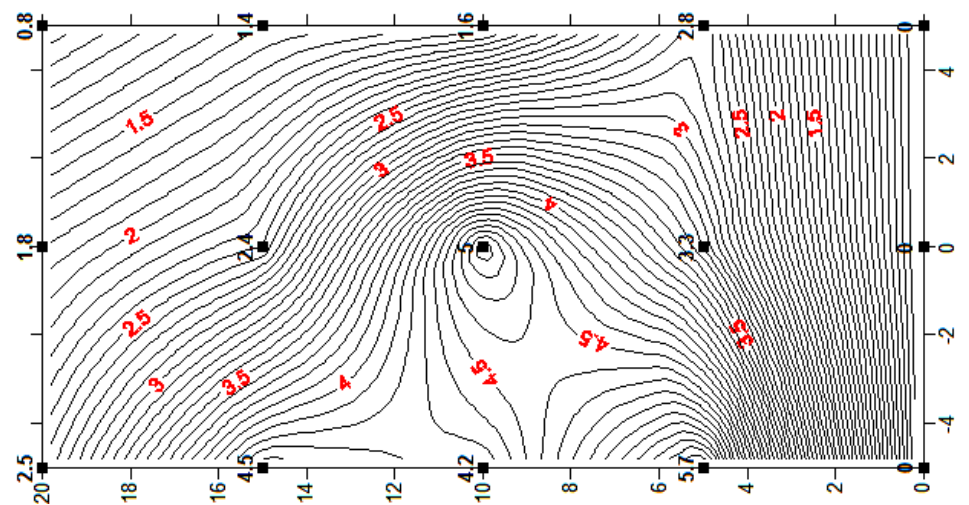

Fig. (4). water distribution pattern, nozzle place, cans spaces and collected water values for fogger.

Average flow rate ranged between 5.43 and $6.96 \mathrm{~L} / \mathrm{h}$.as shown in figure (8).

-For Plastro green, (27 observations, cans spaces $40 \mathrm{~cm}$ ), was ranged between 0.3 to $21.8 \mathrm{~g}$ of water. The following contour map illustrates water distribution, nozzle location, cans places and collected water values for Plastro green nozzle.

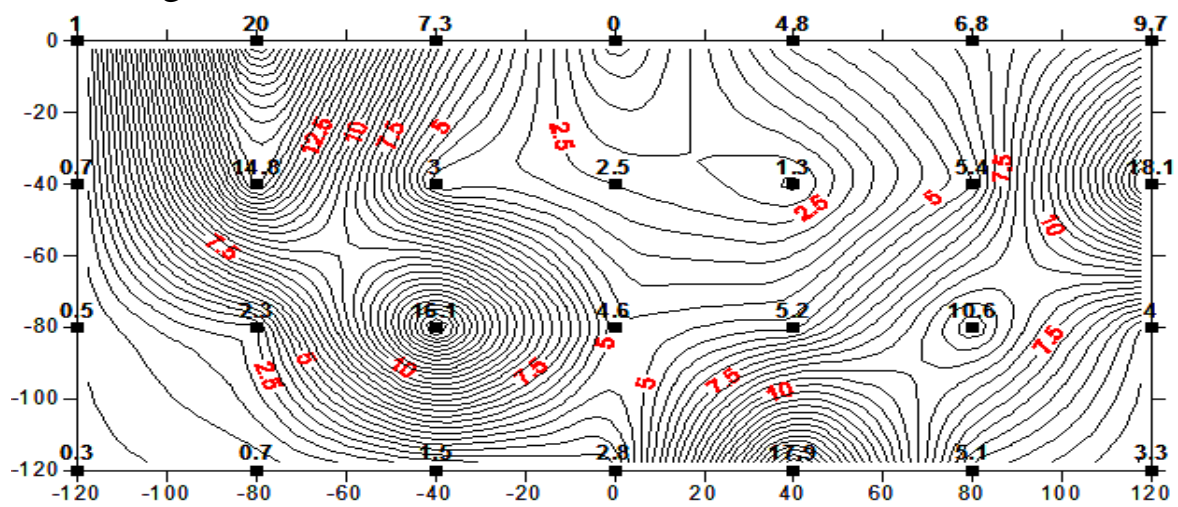

Fig. (5). water distribution pattern, nozzle place, cans spaces and collected water values for Plastro green nozzle . 
Average flow rate ranged between 16.99 and 35.33 L/h.as shown in figure (7).

-For Plastron violet, (24 observations, cans spaces $40 \mathrm{~cm}$, nozzle height $30 \mathrm{~cm}$ ), was ranged between 0.2 to $31.4 \mathrm{~g}$ of water. The following contour map illustrates water distribution, nozzle location, cans paces and collected water values for Plastro violet nozzle.

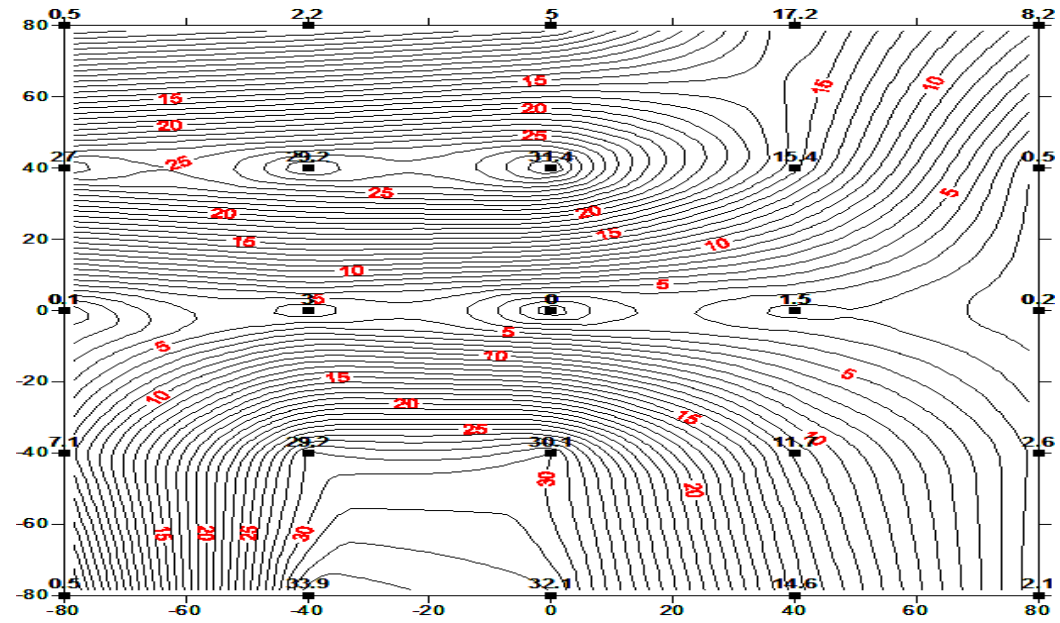

Fig. (6). water distribution, nozzle place, cans spaces and collected water values for Plastro violet nozzle.

Average flow rate ranged between 17.2 and $37.6 \mathrm{~L} / \mathrm{h}$. as shown in figure (7).

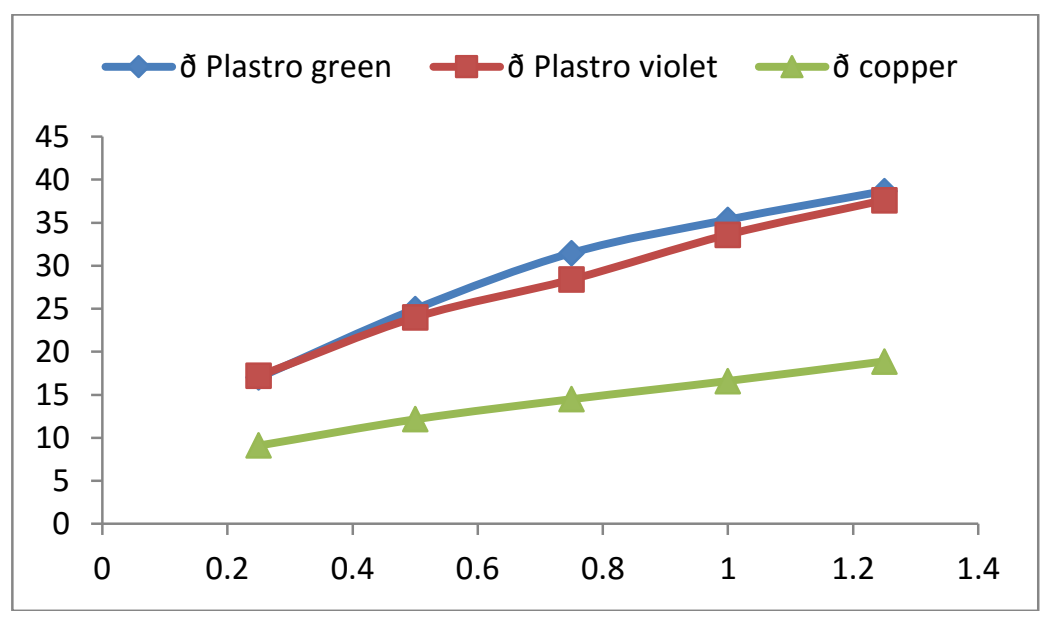

Fig.(7). Relationship between nozzle flow rate vs. operating pressure. 


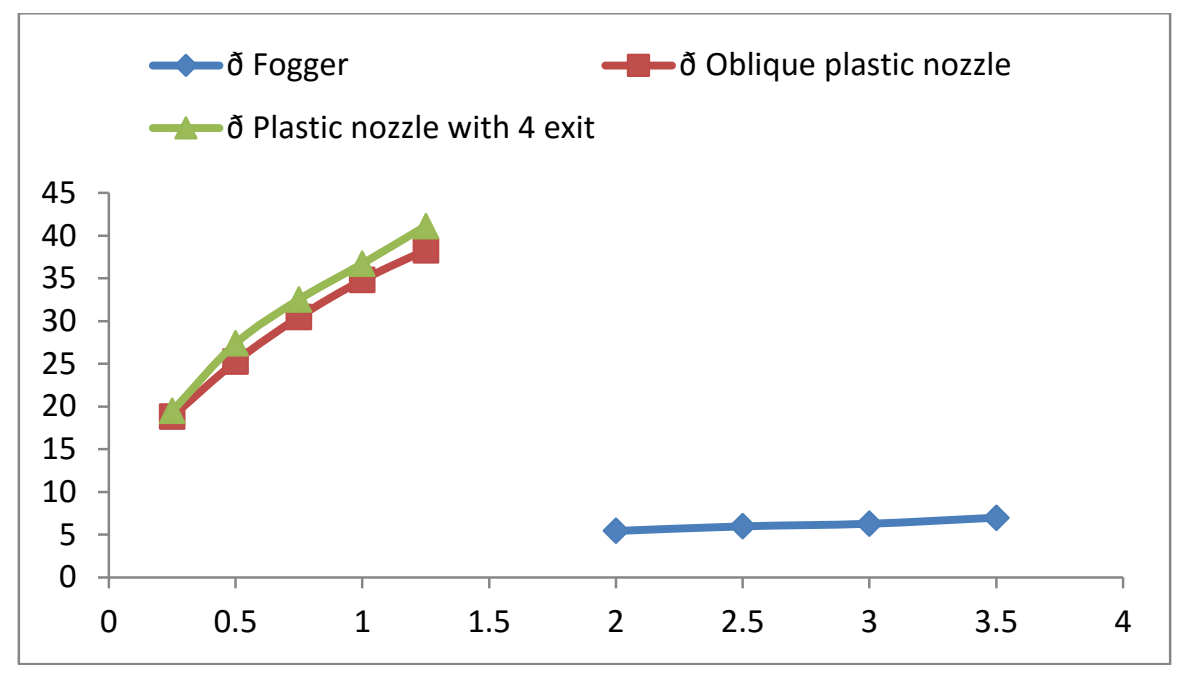

Fig.(8). Relationship between nozzle flow rate vs. operating pressure.

The Copper nozzle, plastic nozzle with 4 exits, single fogger was chosen because terms of highest DU\%, CU\%, wetted diameter and discharge.

The rest nozzles were excluded because of deficiencies in the distribution the three types, the inability to use vertically, and the over flow of discharge and in two of them, the wetted radius were too large and it has irregularly shaped circle.

Based on the tests that have been performed and technically analyzed on different nozzles, in terms of performance, distribution of water and the amount of discharge the copper nozzle was recommended for the further stage of evaluation.

\section{2- Field experiments results}

Copper nozzles were installed on both sides of the vertical spray booms, with four nozzles in both right and left sides (8 nozzle). Vertical spray boom was of $140 \mathrm{~cm}$ height and nozzle spacing was $40 \mathrm{~cm}$ under two operating pressure 1 and 2 bar. The distance between pots line, dimension of track allay and distribution of sampling points are demonstrated in figure(9). 


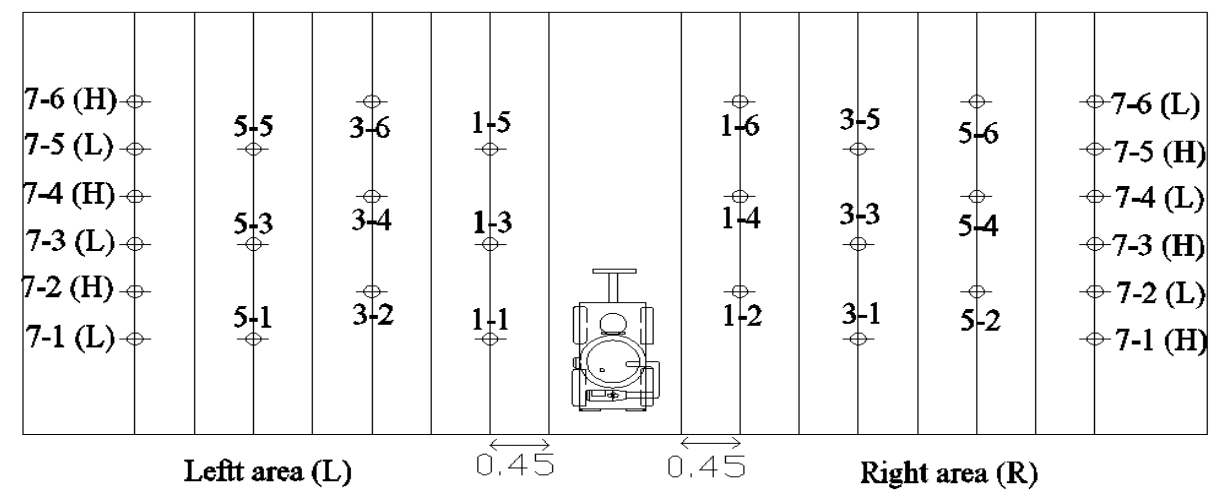

Fig. (9). spacing between plants and machine, water receiving paper places inside greenhouse.

Ten varieties of ornamental plants had maximum height of $180 \mathrm{~cm}$ and minimum heights of $120 \mathrm{~cm}$ were treated. These varieties included (dracaena fragrans, dracaena marginata ,dracaena deremensis ,dracaena tricolor, yucca aloifolia, Yucca variegate, Giant Yucca ,Yucca filamentosa , Syngonium Stick, Pothos Plant stick).Water receiving papers were fixed on the plants leaves to examine distribution of droplets count and pesticide solution coverage percent over plant leaf area.

-The coverage percentage for copper nozzle under2bar, copper nozzle, using water

\begin{tabular}{|c|c|c|c|c|}
\hline \multirow{4}{*}{} & \multicolumn{2}{|c|}{ Right area } & \multicolumn{2}{c|}{ Left area } \\
\cline { 2 - 5 } & Paper place & Coverage \% & Paper place & Coverage $\%$ \\
\cline { 2 - 5 } & $\mathrm{R}(1-2)$ & $100 \%$ & $\mathrm{~L}(1-1)$ & $100 \%$ \\
\cline { 2 - 5 } & $\mathrm{R}(1-4)$ & $100 \%$ & $\mathrm{~L}(1-3)$ & $100 \%$ \\
\cline { 2 - 5 } & $\mathrm{R}(1-6)$ & $100 \%$ & $\mathrm{~L}(1-5)$ & $100 \%$ \\
\cline { 2 - 5 } & $\mathrm{R}(3-1)$ & $100 \%$ & $\mathrm{~L}(3-2)$ & $98.6 \%$ \\
\cline { 2 - 5 } & $\mathrm{R}(3-3)$ & $100 \%$ & $\mathrm{~L}(3-4)$ & $94.3 \%$ \\
\cline { 2 - 5 } & $\mathrm{R}(3-5)$ & $89.2 \%$ & $\mathrm{~L}(3-6)$ & $93 \%$ \\
\cline { 2 - 5 } & $\mathrm{R}(5-2)$ & $94 \%$ & $\mathrm{~L}(5-1)$ & $90 \%$ \\
\cline { 2 - 5 } & $\mathrm{R}(5-4)$ & $89.2 \%$ & $\mathrm{~L}(5-3)$ & $89 \%$ \\
\cline { 2 - 5 } & $\mathrm{R}(5-6)$ & $97.2 \%$ & $\mathrm{~L}(5-5)$ & $95.2 \%$ \\
\cline { 2 - 5 } & $\mathrm{R}(7-1) \mathrm{H}$ & $78.2 \%$ & $\mathrm{~L}(7-1) \mathrm{L}$ & $96 \%$ \\
\cline { 2 - 5 } & $\mathrm{R}(7-2) \mathrm{L}$ & $81.8 \%$ & $\mathrm{~L}(7-2) \mathrm{H}$ & $100 \&$ \\
\cline { 2 - 5 } & $\mathrm{R}(7-3) \mathrm{H}$ & $92.3 \%$ & $\mathrm{~L}(7-3) \mathrm{L}$ & $92 \%$ \\
\cline { 2 - 5 } & $\mathrm{R}(7-4) \mathrm{L}$ & $94.6 \%$ & $\mathrm{~L}(7-4) \mathrm{H}$ & $86.6 \%$ \\
\cline { 2 - 5 } & $\mathrm{R}(7-5) \mathrm{H}$ & $78.6 \%$ & $\mathrm{~L}(7-5) \mathrm{L}$ & $\mathrm{L}(7-6) \mathrm{H}$ \\
\cline { 2 - 5 } & $\mathrm{R}(7-6) \mathrm{L}$ & $83.6 \%$ & & \\
\hline
\end{tabular}


The coverage percentage under 2 bar was about 100-78.2\%.

-Using MALASON/CHEMINOVA 57\%

\begin{tabular}{|c|c|c|c|c|}
\hline \multirow{17}{*}{ 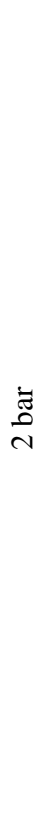 } & \multicolumn{2}{|c|}{ Right area } & \multicolumn{2}{|c|}{ Left area } \\
\hline & Paper place & Coverage $\%$ & Left area & Coverage $\%$ \\
\hline & $\mathrm{R}(1-2)$ & 100 & $\mathrm{~L}(1-1)$ & 87.2 \\
\hline & $\mathrm{R}(1-4)$ & 95 & $\mathrm{~L}(1-3)$ & 100 \\
\hline & $R(1-6)$ & 98.4 & $\mathrm{~L}(1-5)$ & 100 \\
\hline & $\mathrm{R}(3-1)$ & 86.4 & $\mathrm{~L}(3-2)$ & 90.2 \\
\hline & $\mathrm{R}(3-3)$ & 100 & $\mathrm{~L}(3-4)$ & 96 \\
\hline & $\mathrm{R}(3-5)$ & 96.8 & $\mathrm{~L}(3-6)$ & 85.8 \\
\hline & $R(5-2)$ & 80.2 & $\mathrm{~L}(5-1)$ & 80.4 \\
\hline & $\mathrm{R}(5-4)$ & 78.5 & $\mathrm{~L}(5-3)$ & 74.4 \\
\hline & $\mathrm{R}(5-6)$ & 82.8 & $\mathrm{~L}(5-5)$ & 77.8 \\
\hline & $\mathrm{R}(7-1) \mathrm{H}$ & 78.4 & $\mathrm{~L}(7-1) \mathrm{L}$ & 81.8 \\
\hline & $\mathrm{R}(7-2) \mathrm{L}$ & 85.8 & $\mathrm{~L}(7-2) \mathrm{H}$ & 77.2 \\
\hline & $\mathrm{R}(7-3) \mathrm{H}$ & 75.2 & $\mathrm{~L}(7-3) \mathrm{L}$ & 87 \\
\hline & $\mathrm{R}(7-4) \mathrm{L}$ & 87.6 & $\mathrm{~L}(7-4) \mathrm{H}$ & 79.2 \\
\hline & $\mathrm{R}(7-5) \mathrm{H}$ & 73 & $\mathrm{~L}(7-5) \mathrm{L}$ & 89.2 \\
\hline & $\mathrm{R}(7-6) \mathrm{L}$ & 84.4 & $\mathrm{~L}(7-6) \mathrm{H}$ & 73.2 \\
\hline
\end{tabular}

The coverage percentage under 2 bar was about $100-73 \%$.

-Under 2 bar copper nozzle,LambadaCyhalothrine 5\%

\begin{tabular}{|c|c|c|c|c|}
\hline \multirow{17}{*}{$\begin{array}{l}\text { ేี } \\
\text { N }\end{array}$} & \multicolumn{2}{|c|}{ Right area } & \multicolumn{2}{|c|}{ Left area } \\
\hline & Paper place & Coverage $\%$ & Paper place & Coverage $\%$ \\
\hline & $\mathrm{R}(1-2)$ & 100 & $\mathrm{~L}(1-1)$ & 100 \\
\hline & $\mathrm{R}(1-4)$ & 100 & $\mathrm{~L}(1-3)$ & 100 \\
\hline & $\mathrm{R}(1-6)$ & 100 & $\mathrm{~L}(1-5)$ & 100 \\
\hline & $\mathrm{R}(3-1)$ & 98 & $\mathrm{~L}(3-2)$ & 92.6 \\
\hline & $\mathrm{R}(3-3)$ & 89.2 & $\mathrm{~L}(3-4)$ & 100 \\
\hline & $\mathrm{R}(3-5)$ & 95.2 & $\mathrm{~L}(3-6)$ & 98.6 \\
\hline & $\mathrm{R}(5-2)$ & 71.8 & $\mathrm{~L}(5-1)$ & 80 \\
\hline & $\mathrm{R}(5-4)$ & 81 & $\mathrm{~L}(5-3)$ & 87 \\
\hline & $\mathrm{R}(5-6)$ & 76.4 & $\mathrm{~L}(5-5)$ & 83.8 \\
\hline & $\mathrm{R}(7-1) \mathrm{H}$ & 73 & $\mathrm{~L}(7-1) \mathrm{L}$ & 92.6 \\
\hline & $\mathrm{R}(7-2) \mathrm{L}$ & 85.8 & $\mathrm{~L}(7-2) \mathrm{H}$ & 75.2 \\
\hline & $\mathrm{R}(7-3) \mathrm{H}$ & 70.4 & $\mathrm{~L}(7-3) \mathrm{L}$ & 87.2 \\
\hline & $\mathrm{R}(7-4) \mathrm{L}$ & 82.4 & $\mathrm{~L}(7-4) \mathrm{H}$ & 75.2 \\
\hline & $\mathrm{R}(7-5) \mathrm{H}$ & 73.8 & $\mathrm{~L}(7-5) \mathrm{L}$ & 88.4 \\
\hline & $\mathrm{R}(7-6) \mathrm{L}$ & 82.4 & $\mathrm{~L}(7-6) \mathrm{H}$ & 81.8 \\
\hline
\end{tabular}

The coverage percentage under 2 bar was about $100-70.4 \%$. 
The delivery of water and pesticide in the two sides of the greenhouse under two bar pressure when the plant was at a distance of $45 \mathrm{~cm}$ from the machine, the coverage was $100 \%$ when using water, $96.7 \%$ when using malation and $100 \%$ when using lambada.The coverage at a distance of $135 \mathrm{~cm}$ was $97.6 \%$ with water, $92.5 \%$ when using malation and 95.2 when using lambada. The coverage at distance of $225 \mathrm{~cm}$ was $90.7 \%$ with water, $79 \%$ in malation and $81.6 \%$ in lambada.The coverage at distance of 315 at height $180 \mathrm{~cm}$ was $87.1 \%$ and at height $120 \mathrm{~cm}$ was 90.6 in water case, with malation at height of $180 \mathrm{~cm}$ was $76 \%$, at height of $120 \mathrm{~cm}$ was $85.9 \%$ and when using lambada at height of $180 \mathrm{~cm}$ it was $74.8 \%$, at $120 \mathrm{~cm}$ was 86.4 . Different efficiencies of spraying was based on the different density of the liquid but it was not less than $70 \%$ in all cases and the coverage of the plants leaf ranged between $100-70 \%$ in all cases. It is recommended to use copper nozzle with the vertical spray boom, because of the efficiency of delivery, distribution, discharge and spraying diameter.

\section{CONCLUSION}

Laboratory tests proved that the best nozzle in terms of operating was copper nozzle, which achieved best distribution, covering and best wetted radius. Therefore, it was chosen to be fixed on the manufactured vertical spray boom machine to be tested inside greenhouse. Field experiments were conducted inside the greenhouse and the results showed that the percentage of crop coverage with the various different plants heights and distances from the machine was $100-70 \%$ of coverage with different densities of the used liquids (water - pesticide).

\section{REFERENCES:}

Abuarab,M.E.,M. H., Hassan,A. E. Badr, M. El-Sherbini. (2008). Water and soil moisture distribution patterns under micro sprinkler irrigation systems. Ph. D. Thesis. Department of Agricultural Engineering, Faculty of Agriculture, Cairo University. 
Braekman, P., D. Foque., M. C. Labeke, G. Pieters and D. Nuyttens. (2009) Influence of spray application technique on spray deposition in greenhouse ivy pot plants grown on hanging shelves, HORTSCIENCE, 44(7):1921-1927.

Braekman, P. , D. Foque, W. Messens, M.C. Van Labeke, J G Pietersd and D. Nuyttens. ( 2007). Effect of spray application technique on spray deposition in greenhouse strawberries and tomatoes. ASABE Annual International Meeting, (April 2009), P: 203-212.

Burks, T. (2006). Development of a prototype greenhouse robotic sprayer system, FNGLA, Endowed Research Fund, Florida Agricultural Experiment Station, Agricultural and Biological Engineering Dept, University of Florida. USA.

Derksen, R., C. Ranger, L.A. Cañas, J.C. Locke, H. Zhu and C. R. Krause.(2009).Comparison of handgun and boom spray delivery systems for greenhouses. ASABE Annual International Meeting.Paper Number: 097453.

Derksen, R., J. Frantz, C. Ranger, J. Locke, H. Zhu and C. Krause.(2007)a. The effect of spray volume and quality on handgun delivery of pesticides to greenhouse plants.ASABE Annual International Meeting.2950 Niles Roads, St. Joseph, Michigan 49085-9659. USA.

Fritz, B., W. C. Hoffmann and W. E. Bagley.(2010). Effects of spray mixtures on droplet size under aerial application conditions and implications on drift. ASABE, Vol. 26(1): 21-29.

Miller P., A. Lane and H. Wheeler.(2001).Matching spray applications to canopy characteristics in cereal crops Princeton Architectural Press, New York, ISBN 1-56898-242-9 
Nuyttens D., M. De Schampheleire, K. Baetens and B. Sonck.(2007). The influence of operator-controlled variables on spray drift from field crop sprayers. ASABE, Vol. 50(4): 1129-1140

Nuyttens D., M. De Schampheleire, P. Verboven, E. Brusselman and D. Dekeyser.(2009). Droplet size and velocity characteristics of agricultural sprays. ASABE, Vol. 52(5): 1471-1480.

Nuyttens, D., S. Windey and B. Sonck .(2004). Optimization of a vertical spray boom for greenhouse sprayapplications. Biosystems Engineering.P: 417-423.

Pascuzzi S., A. Guarella. (2008). Pesticide application over covered crops with hand held equipment: analysis of the contaminations. International Conference: September 15-17, 2008 Ragusa - Italy

Van Os, E.A., J.M.G.P. Michielsen, F.J.M. Corver, J.V. van den Berg, M.A. Bruins, H.A.J. Porskamp and J.C. van de Zande.(2005). Reduction of spray pressure leads to less emission and better deposition of spray liquid at high-volume spraying in greenhouse tomato. WUR-Agro technology and Food Innovations, Wageningen, Netherlands.

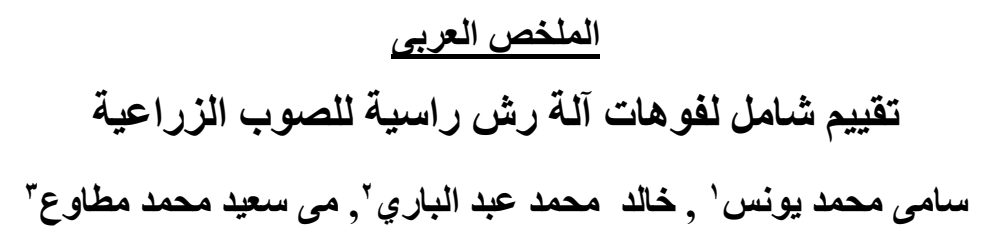

أجري البحث الحالي بهدف عمل تقييم شامل لبعض أنواع فوهات آلات الرش الرأسية

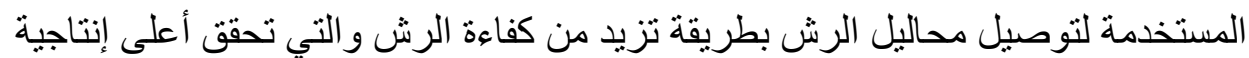

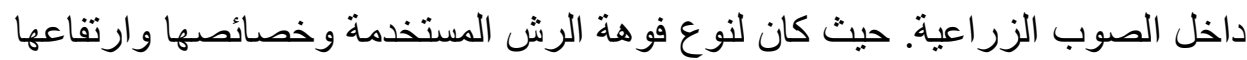

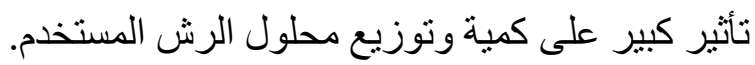

'أستاذ ـ قسم الهنسةة الزراعية ـ كلية الزراعةـ جامعة القاهرة.

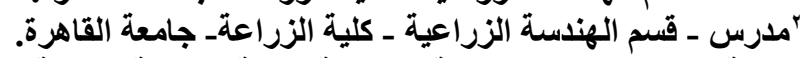
"طالبة ماجيستير-قسم الهندسة الزراعية ـ كلية الزراعةـ جامعة الزعة القاهرة. 
تم اختبارومعايرة 7 أنواع مختلفة من فوهات الرش باستخدام ضغوط نشغيل مختلفة لكل

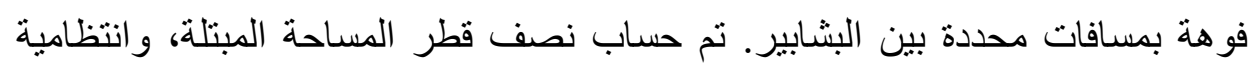

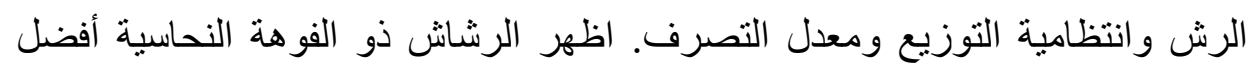

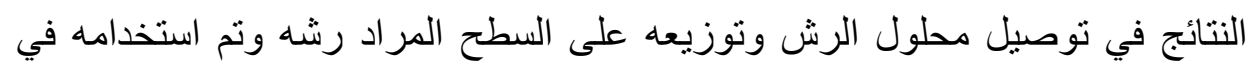

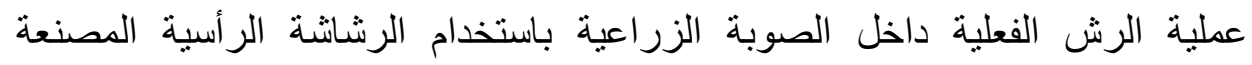

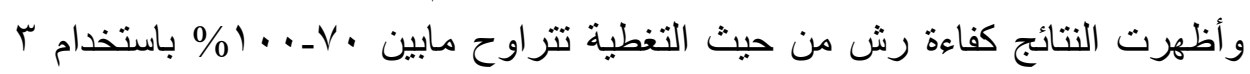

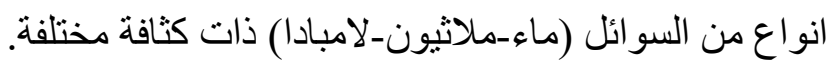

الكلمات الدالة: صوبة ـ توصيل-مقاومة آفات - بيئة - حامل رأسى- نموذج تجريبىتوزيع. 